\title{
25 Research Square \\ Genetic Structure in Neotropical Birds with Different Tolerance To Urbanization
}

\section{Mauricio Rodríguez-Bardía ( $\sim$ maurod.96@gmail.com )}

Programa de Posgrado en Biología, Sistema de Estudios de Posgrado, Universidad de Costa Rica. San

Pedro, San José, 11501-2060

Eric J. Fuchs

Escuela de Biología, Universidad de Costa Rica. San Pedro, San José, 11501-2060

\section{Gilbert Barrantes}

Escuela de Biología, Universidad de Costa Rica. San Pedro, San José, 11501-2060

\section{Ruth Madrigal-Brenes}

Escuela de Biología, Universidad de Costa Rica. San Pedro, San José, 11501-2060

\section{Luis Sandoval}

Escuela de Biología, Universidad de Costa Rica. San Pedro, San José, 11501-2060

\section{Research Article}

Keywords: Aves, urban adaptation, population genetics, genetic diversity, gene flow, circuit-theory

Posted Date: December 16th, 2021

DOI: https://doi.org/10.21203/rs.3.rs-1125247/v1

License: (c) (i) This work is licensed under a Creative Commons Attribution 4.0 International License.

Read Full License

Version of Record: A version of this preprint was published at Scientific Reports on April 11th, 2022. See the published version at https://doi.org/10.1038/s41598-022-09961-9. 


\section{Abstract}

Gene flow in birds can be affected by urbanization depending on natural history traits and adaptability to habitat change. Contrasting results can be expected when comparing species with opposite resilience to urbanization. In this study, we assessed genetic diversity and structure for two bird species, the urban avoider white-eared ground-sparrow, Melozone leucotis, and the urban dweller house wren Troglodytes aedon. We used seven microsatellite loci and sampled five locations with differing levels of urbanization in Costa Rica. We found considerably higher genetic structure in white-eared ground-sparrows than in house wrens. Circuit theory analyses proved a higher isolation from urban resistance for the white-eared ground-sparrow than for house wrens. These results support that urbanization is a significant barrier for gene flow in urban avoiders, in contrast to urban dweller species that showed little to no impact. Differences could be attributed to a higher plasticity in habitat and nesting site preferences in the house wren, and significant dispersal limitation for the white-eared ground-sparrow. These results emphasize the need for conservation strategies towards white-eared ground-sparrows and other urban avoider species whose habitat and connectivity have been reduced by the recent urban expansion.

\section{Introduction}

The rapid expansion of urbanized areas has converted large extensions of natural habitats into a concrete jungle that surrounds some small natural or seminatural fragments of vegetation ${ }^{1-5}$. The adaptive response to such drastic changes varies widely among species. Some species experience isolation and population decline, and become locally extinct 1,6,7. For some species ("urban avoiders"), buildings, streets, highways, and other human settlements restrict their movement, reducing the connection within the metapopulation ${ }^{8-10}$. These barriers are expected to reduce gene flow and genetic diversity, increasing inbreeding coefficient, allele fixation and genetic structure of those species trapped in isolated vegetation tracts ${ }^{11}$. However, contrasting results are expected for those species for which

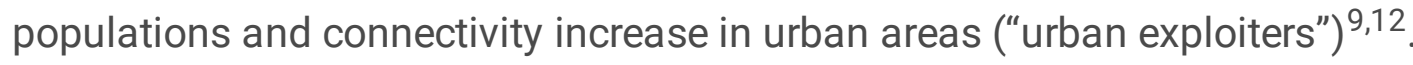

The effect of urbanization on gene flow and other population genetic parameters will depend on each species' mobility and life history traits ${ }^{13}$. In birds, species tolerance and adaptability to urban environments determines the impact of negative effects from habitat fragmentation and isolation ${ }^{12}$. In wrentits (Chamaea fasciata), a species with low dispersion capabilities, major roads restricted gene flow between fragments in urban landscape, producing a strong genetic structure across populations ${ }^{14}$. Similarly, in a species with high dispersion capabilities as song sparrow (Melospiza melodia) urban land cover has also shaped its genetic structure ${ }^{15}$. In this case higher genetic structure occurred in sites isolated and surrounded by dense and old urban development, compared to more recently developed urban sites or between forest relics ${ }^{15}$. However, in low-density urbanized sites, song sparrows showed no evidence of population genetic structure, suggesting that this species is capable of maintaining sufficient gene-flow between sites in non-saturated urban landscapes ${ }^{16}$. In great tits (Parus major), differences in patch size, population size and fragmentation can have different effects over levels of genetic structure 
$12,17,18$. The distance between patches within an urban matrix has reduced the connectivity between patches, and increased the genetic structure for the Singaporean yellow-breasted babbler (Mixornis gularis), a tropical edge-tolerant species ${ }^{19}$. These examples suggest that the effects of urbanization on structuring population genetics vary within and between species.

It is possible to use different approaches to evaluate the effects of urbanization on gene flow and genetic structure. Methods based on circuit-theory are well fitted to evaluate the effect of the complex connectivity structure within urban habitats on the genetic structure of mobile individuals such as birds 20 . This method focuses on random walking and multiple-choice path algorithms to uncover current flow in a resistance matrix developed from geographic information systems (GIS) ${ }^{20}$. With this algorithm landscape resistance hypotheses can be proposed, assigning a resistance value to different landscape components, forest cover, altitude or topological characteristic layers based on each species natural history and habitat use. Values of cumulative resistance between populations are used to test for correlations with genetic structure ${ }^{15}$.

In this study, our main objective was to evaluate the effect of urbanization on genetic diversity and gene flow patterns of two neotropical bird species with different levels of resilience to urbanization, across a heterogeneous landscape of urbanization and agriculture in Costa Rica. The white-eared ground-sparrow (Melozone leucotis) inhabit thickets, coffee plantations and secondary forest edges ${ }^{21-23}$. Historically, coffee industry expansion in the 20th century presumably provided greater connectivity for white-eared ground-sparrow, but in recent years, this habitat type has been gradually transformed into urban settlements and the habitat of white-eared ground-sparrows has been converted into fragments that vary in isolation ${ }^{1,24-26}$. On the contrary, the second species included in this study, the house wren (Troglodytes aedon), is commonly found in open and semi-open areas, forest edges and it has presumably benefited from urban development $21,27,28$. Their territories are smaller in more urbanized areas, and this has been associated with an increase in nesting and food resources ${ }^{27}$. To date, there is a paucity of studies that evaluate the impact of recent habitat fragmentation and habitat loss on genetic diversity and structure of tropical species that differ in their response to the changes imposed by urbanization.

\section{Results}

One marker for each species was monomorphic (As $\mu 18$ and ThPl-01) across all populations, so we removed them from further analyses. For white-eared ground-sparrow, only Mme7 deviated from Hardy Weinberg Equilibrium (HWE) as expected for a sex-linked marker. To include it in further analysis, the missing allele was coded as missing for females and juveniles ${ }^{15}$. Locus heterozygosity $\left(H_{0}\right)$ ranged between 0.347 and 0.903 and $H_{e}$ ranged $0.368-0.891$ for white-eared ground-sparrows (Supplementary Table S1). In house wren, locus $H_{o}$ ranged between 0.107-0.904, while $H_{e}$ ranged from 0.101 to 0.870 (Supplementary Table S1). Overall, $H_{e}$ was consistently higher for white-eared ground-sparrows $(0.639$, $95 \% \mathrm{Cl}=0.510$ and 0.785$)$ than for house wren $(0.519,95 \% \mathrm{Cl}=0.327$ and 0.711$)$, though confidence 
intervals of diversity estimates overlapped between species. Inbreeding was not observed in any species, but we found a heterozygote excess in white-eared ground-sparrow in the UCR subpopulation (Table 1).

Table 1

Mean $( \pm S D)$ observed heterozygosity $\left(H_{0}\right)$, expected heterozygosity $\left(H_{e}\right)$, inbreeding coefficient $\left(\mathrm{F}_{I S}\right)$ and allelic richness $\left(\mathrm{A}_{\mathrm{r}}\right)$ for each population assessed for white-eared ground-sparrow (Melozone leucotis) and house wren (Troglodytes aedon).

\begin{tabular}{|c|c|c|c|c|c|c|}
\hline Species & Population & $n$ & $\mathrm{H}_{0}$ & $\mathrm{H}_{\mathrm{e}}$ & $F_{I S}$ & $A_{r}$ \\
\hline \multirow[t]{8}{*}{ Melozone leucotis } & MTV & 12 & 0.655 & 0.640 & -0.048 & 5.86 \\
\hline & & & \pm 0.243 & \pm 0.256 & \pm 0.139 & \\
\hline & $\mathrm{HDA}$ & 12 & 0.667 & 0.620 & -0.104 & 5.57 \\
\hline & & & \pm 0.180 & \pm 0.222 & \pm 0.127 & \\
\hline & UCR & 13 & 0.615 & 0.518 & -0.215 & 4.94 \\
\hline & & & \pm 0.335 & \pm 0.309 & \pm 0.127 & \\
\hline & $J B L$ & 19 & 0.597 & 0.570 & -0.057 & 4.54 \\
\hline & & & \pm 0.223 & \pm 0.207 & \pm 0.186 & \\
\hline \multirow[t]{10}{*}{ Troglodytes aedon } & MTV & 11 & 0.468 & 0.489 & 0.025 & 3.76 \\
\hline & & & \pm 0.321 & \pm 0.273 & \pm 0.297 & \\
\hline & HDA & 11 & 0.416 & 0.468 & 0.096 & 4.37 \\
\hline & & & \pm 0.310 & \pm 0.297 & \pm 0.308 & \\
\hline & UCR & 16 & 0.411 & 0.483 & 0.140 & 4.08 \\
\hline & & & \pm 0.318 & \pm 0.317 & \pm 0.259 & \\
\hline & $J B L$ & 13 & 0.517 & 0.522 & -0.017 & 4.45 \\
\hline & & & \pm 0.287 & \pm 0.283 & \pm 0.183 & \\
\hline & COR & 10 & 0.500 & 0.460 & -0.095 & 3.00 \\
\hline & & & \pm 0.245 & \pm 0.226 & \pm 0.214 & \\
\hline
\end{tabular}

We found significant genetic structure in both species, but it was higher in white-eared ground-sparrow $\left(\theta_{W C}=0.0872,95 \% \mathrm{Cl}=0.0463\right.$ and 0.1411$)$ than in house wren $\left(\theta_{W C}=0.0610,95 \% \mathrm{Cl}=0.0422\right.$ and 0.0736). Pairwise $F_{S T}$ differed significantly between all but one comparison (UCR and HDA) for whiteeared ground-sparrow (Supplementary Table S2). For house wren, only MTV and COR had significant differences in allele frequencies from all the other populations, while UCR and JBL marginally differ between each other (Supplementary Table S2). 
In white-eared ground-sparrow MTV clustered separately from the rest of the populations, HDA and UCR grouped together and JBL separated from HDA and UCR on the second axis (Fig. 1), using DAPC clustering with priors defined as sampling sites. In contrast, for house wren, UCR, HDA, JBL and MTV clustered closely together, while individuals from COR were genetically separated from all other populations (Fig. 2). The Evanno method grouped individuals into $K=4$ clusters, with $K=2$ as another possible configuration (Supplementary Fig. S1), as $K=2$ clusters had the highest likelihood (Supplementary. Fig. S1). For $K=4$, clusters 1, 2 and 3 included individuals from MTV, HDA and UCR, and individuals from HDA and UCR had higher proportion of cluster 4 assignation than MTV (Fig. 3a). JBL individuals were mostly assigned to cluster 4 , and less than half the individuals were grouped in the other three clusters (Fig. 3a). With $K=2$, all MTV individuals were assigned to Cluster 1, while HDA, UCR and JBL individuals represented a mixture from both clusters (Fig. 3b). For house wren, the Evanno method indicated that $K=2$ was the most likely configuration, but the highest $L(K)$ corresponds to $K=1$ (Supplementary Fig. S1). Individuals from each population of house wren were equally assigned to both clusters, suggesting a single panmictic population (Fig. 3c).

We found significant IBD for white-eared ground-sparrow $(r=0.469, p<0.001)$ but not for house wren $(r=$ $0.066, p=0.184$ ). The urban resistance circuit analysis showed high connectivity between UCR and HDA, and lower connectivity among JBL and both HDA and UCR, for both species (Fig. 4). Connectivity between MTV and all other populations was low, as was COR for house wren (Fig. 4a-b). We found that the urban resistance matrixes correlated with genetic differences for both species, but correlations were higher for white-eared ground-sparrow (white-eared ground-sparrow: $r=0.350, p<0.001$; house wren: $r=0.114, p=0.020)$.

Our niche modelling predicted that white-eared ground-sparrow should be restricted to the forested areas between the central valley of Costa Rica and MTV (Fig. 5a). For house wren, we found a countrywide suitability (Fig. 5b). Climatic resistance values correlated with genetic Euclidean distances for both species, but with a higher correlation for white-eared ground-sparrow $(r=0.453, p<0.001$; Fig. $5 c)$ than for house wren ( $r=0.100, p=0.034$; Fig. $5 d)$.

\section{Discussion}

We found that urbanization affected gene flow differently for both species. Urbanized areas do not represent a barrier for house wren, consequently this species appears to be a single panmictic population in Costa Rica. On the contrary, gene flow is restricted by urban development in white-eared groundsparrow. Using microsatellites, our analyses showed higher genetic structuring in white-eared groundsparrow than in house wren. STRUCTURE and DAPC suggested differences in allele frequencies among white-eared ground-sparrow populations, while clustering all house wren individuals into a single group.

Genetic diversity estimates were similar for both species because confident intervals overlapped. These results contradict our initial predictions, since we expected a higher genetic diversity for house wren which is an urban tolerant species that shows great plasticity in habitat and nesting site preferences ${ }^{27-}$ 
On the other hand, we expected white-eared ground-sparrow to have less genetic diversity since this species is isolated in small populations that are expected to experience higher genetic drift ${ }^{12,27}$. Similar results were found in two European bird species. In this study the tolerant blue tit (Cyanistes caeruleus) and less tolerant great tit, both species had similar genetic diversity in an urban area, even when genetic structure was significantly higher for great tit than for blue tit ${ }^{30}$. Other studies have reported similar genetic diversity estimates between urban and rural populations of the same bird species (e.g., song sparrow; burrowing owl, Athene cunicularia; house sparrow, Passer domesticus) ${ }^{16,31,32}$. Therefore, our results may be explained because both species have large effective population sizes due to the recent urbanization in the study area (<60 years) ${ }^{33}$, which is not sufficient to reduce population sizes and consequently genetic diversity through drift. This will be particularly true given that habitat fragmentation has occurred gradually ${ }^{33}$, which probably allowed remnant forest patches to act as stepping-stones for gene flow in the last three decades $1,24,34$

Clustering algorithms suggest that urbanization functions as barriers to gene flow in white-eared groundsparrow, genetically structuring its populations, but in contrast, all populations of the house wren in Costa Rica may be considered a large panmictic population. Habitat loss and fragmentation often limit connectivity and gene flow and, consequently, increase differences in allele frequencies between populations ${ }^{35}$. Multiple studies have shown how urban areas increase fragmentation and isolation of avian populations with the corresponding effects on genetic diversity $14,15,18,19,30$. However, the magnitude of the effects of urbanization varies among species. For example, differences in sensitivity to urbanization resulted in higher genetic structure for great tits than for blue tits in Poland, in which fragmentation (urban $v s$. forest) and isolation by urban areas limited gene flow for great tits but did not for blue tits ${ }^{30}$. The authors attribute these differences to the greater migration and dispersal ability of blue tits in urban populations ${ }^{30}$. Tan et al. ${ }^{19}$ also found that the effective population size of the forestedge tolerant Singaporean yellow-breasted babbler correlates with the habitat contraction caused by urbanization. Genetic differences in urban subpopulations were attributed to small effective population sizes, limited dispersal, and a lack of connectivity between patches ${ }^{19}$. The differences we observed on genetic structure between white-eared ground-sparrow and house wren may also be explained by contrasting tolerance to urbanization between these two species ${ }^{27}$. White-eared ground-sparrow and house wren differ in how they can benefit from urban habitats. White-eared ground-sparrow feeds in the humid leaf litter and requires thickets to build nests, while house wren feeds on arthropods on a wide array of substrates and can build nests in buildings and human made cavities ${ }^{22,27-29}$. A large proportion of the original habitat occupied by white-eared ground-sparrow in Costa Rica is now located within the Greater Metropolitan Area (GAM), characterized by a recent, rapid, and unplanned urban development ${ }^{36}$. For the earlier half of the 20th century, a large portion of the GAM was covered by coffee plantations and second growth vegetation, but recent urban development has reduced coffee plantations and natural vegetation cover to small, isolated fragments ${ }^{1,26}$. Hence, the preferred habitat of white-eared groundsparrow has been constantly reduced; threatening the viability of this species' populations ${ }^{25,37,38}$. 
House wren inhabits a wider array of habitats and can move between populations across large, urbanized areas ${ }^{29}$. Accordingly, we were not able to find evidence of isolation by distance or by habitat resistance. However, we found intermediate levels of genetic structure attributed to its likely low natal dispersal, because young individuals do not need to move long distances to find suitable habitat ${ }^{39}$. However, this hypothesis does not explain why we did not find significant IBD. This issue will be discussed below in further detail.

From the four populations of white-eared ground-sparrow, two (HDA and UCR, Fig. 1) were clustered together. These two populations are separated by the shortest distance and likely interconnected through remnant coffee plantations and patches of second growth vegetation. This suggests that gene flow for white-eared ground-sparrow is dispersal limited due possibly to urban areas limiting migration among populations ${ }^{27}$. JBL is separated from HDA and UCR by a large, urbanized area of approximately 2280 ha 40 , and by a mountainous densely forested terrain which likely limited migration and gene flow. These results are supported by the high correlation between urban resistance and genetic differentiation for white-eared ground-sparrow. MTV is geographically the most distant site, but clustered closer to HDA and UCR, due to large patches of coffee plantations located among these sites ${ }^{37}$. Contrary to white-eared ground-sparrow, our results suggest that house wren may be a single panmictic metapopulation. This is supported by the lack of IBD, and the weak correlations between genetic differentiation with urban resistance and climatic resistance. These results support our initial expectations that this species benefits from the recent urban development which increases the availability of nesting sites and habitat use, thus increasing connectivity among populations ${ }^{27,29}$. In contrast we expect gene flow to decrease for whiteeared ground-sparrow in future generations. This is expected for city populations of an urban avoider that may reach the lowest densities in urban areas 9,27 .

All our isolation models suggest that geographic distance, urban resistance, and climatic resistance limit gene flow for white-eared ground-sparrow. Distance accounted for the strongest effect on genetic structure, which suggests that this species has limited dispersal, probably related to its territoriality 41,42 , low natal dispersal, and philopatry, though this remains to be tested. The geographic distribution of this species in Costa Rica, which coincides with the largest urbanized area, further limits movement between populations as indicated by the high correlation between the resistance matrix and genetic structure $23,43,44$. Another study using circuit theory analysis showed a similar effect from urbanization on population differentiation in song sparrow populations, concluding that urbanization reduces gene flow in a mobile, disturb-tolerant species ${ }^{15}$. Other studies have drawn similar conclusions, finding that habitat fragmentation caused by urbanization expansion affects gene flow among isolated populations, particularly for species with a limited adaptive response to such drastic changes $14,15,30$.

In contrast, genetic structure did not correlate with distance in house wren, though genetic structure correlates weakly with environmental resistance. These results may be related to its widespread distribution and tolerance to changes imposed by urbanization. The house wren is a generalist species that nests in different man-made cavities and feeds on arthropods from a large variety of substrates ${ }^{28,29}$. 
However, 20 years ago, a study of six house wren populations in Costa Rica found significant IBD and genetic structure ${ }^{39}$. The differences findings of both studies may be attributed to the rapid urban expansion that occurred during the last 20 years in Costa Rica, which likely has increased the dispersal and gene flow for house wren. Additionally, most populations studied by Arguedas \& Parker ${ }^{39}$ at that time were separated by forested areas, which is a barrier of dispersion for this species, producing less connected populations.

Our results provide evidence for the need of conservation strategies and management for non-resilient species whose habitat has been reduced to small fragments immersed in urban matrices. The neotropics is the most avian diverse region, but the rapid growth of overcrowded cities poses a risk for urban avoider birds ${ }^{1,45,46}$. This is the case of white-eared ground-sparrow that may struggle to withstand the effects of the uncontrolled sprawl of Costa Rican urbanization ${ }^{36}$. Urban expansion will further isolate white-eared ground-sparrow populations and reduce their available habitat, increasing the effect of drift and inbreeding, which may increase the risk of local extinction 47,48 . Other species with similar ecology and behavior than white-eared ground-sparrow may be exposed to the same consequences of urbanization. It is then urgent to implement management and conservation strategies that ameliorate the negative effects of urbanization expansion on the rich Costa Rican avifauna ${ }^{1}$.

In conclusion, our study shows that the effect of unplanned urbanization sprawl on genetic diversity may strongly depend on a species ecology and behavior. Our results indicate that urbanization limits gene flow and has an effect in the genetic structure of white-eared ground-sparrow, but barely affects house wren. Such differences are associated with differences in tolerance to urban ambient and the resources that these landscapes offer to each species. White-eared ground-sparrow is more sensitive to urbanization and habitat loss than house wren, which may result in lower diversity if habitat availability is further reduced. We are aware that our sample sizes may limit our conclusions, however, differences between species were consistent across all our analyses and our results contribute to the scant information on the vulnerability of city avoider species, such as white-eared ground-sparrow. Studies on gene flow in neotropical cities are fundamental to implement conservation strategies that increase connection between patches of natural vegetation immersed in extensive urban matrices.

\section{Methods}

\section{Study site}

We selected four sites for white-eared ground-sparrow (Fig. 6), three located within the Greater Metropolitan Area of Costa Rica (GAM). This is the most densely populated and urbanized area of the country, and though some remaining coffee, sugarcane, and other plantations are still present; most of the area is urbanized. We sampled individuals in Heredia province (HDA: $10^{\circ} 01^{\prime} \mathrm{N}, 84^{\circ} 05^{\prime} \mathrm{W}$, altitude: $1200-$ $1500 \mathrm{~m}$ ); University of Costa Rica Campus, San José Province (UCR: $09^{\circ} 56^{\prime} \mathrm{N}, 84^{\circ} 05^{\prime} \mathrm{W}$, altitude: $1200 \mathrm{~m}$ ); and Lankester Botanical Garden, Cartago Province (JBL: $09^{\circ} 50^{\prime} \mathrm{N}, 83^{\circ} 53^{\prime} \mathrm{W}$, altitude: $\left.1400 \mathrm{~m}\right)$. Both Lankester Botanical Garden and University of Costa Rica Campus are urban areas with small patches of 
secondary vegetation immersed in an urban matrix. HDA had a lower urban coverage, surrounded by both urban zones and coffee plantations. The other sampling site was Monteverde, in the Puntarenas province (MTV: $10^{\circ} 18^{\prime} \mathrm{N}, 84^{\circ} 48^{\prime} \mathrm{W}$; altitude: $1600 \mathrm{~m}$ ), characterized by low density population, coffee plantations, and large forest patches that connect with more extensive mature forests.

For house wren, we collected individuals in five localities (Fig. 6); three of these localities were the same sampling sites of white-eared ground-sparrow: HDA, UCR and JBL. The MTV sampling site of house wren was located about $5 \mathrm{~km}$ south of the white-eared ground-sparrow sampling site $\left(10^{\circ} 16^{\prime} \mathrm{N}, 84^{\circ} 47^{\prime} \mathrm{W}\right.$, altitude: $1090 \mathrm{~m})$. The fifth sampling site was in Corredores, in the Puntarenas Province (COR: $08^{\circ} 35^{\prime} \mathrm{N}$, $82^{\circ} 58^{\prime} \mathrm{W}$; elevation $11 \mathrm{~m}$ ), and is characterized by extensive oil palm plantations.

\section{Sample collection}

We captured individuals of white-eared ground-sparrow using mist nets upon song playback in 2012, 2013, and 2019-2021, capturing between 12 to 19 individuals per site. House wren individuals were captured using mist nets upon song playback in 2019-2021, capturing between 11 and 16 individuals per site. We color banded all collected individuals, sexed all adults, and categorized juveniles as indeterminate. We collected $10-30 \mu \mathrm{L}$ of blood from the brachial vein for each individual and stored it in $95 \%$ ethanol or Lysis buffer for molecular analyses ${ }^{49}$. Anesthesia was not used, and all birds were released unharmed. Procedures were conducted in accordance with the current laws in Costa Rica. Research permits and animal handling protocols were approved by the Research Committee of Biology School and by the Animal Care Committee (ACC) of Universidad de Costa Rica under the project approval code B9-469 and C1-085 of Vicerrectoría de Investigación. All procedures were conducted following the regulations of the ACC.

\section{DNA extraction and SSR amplification}

We extracted DNA from blood and muscle tissue using the DNeasy blood and tissue Kit (Qiagen Inc., Valencia, CA, USA). For white-eared ground-sparrow, we amplified eight primers: Mme2, Mme7, Mme8,

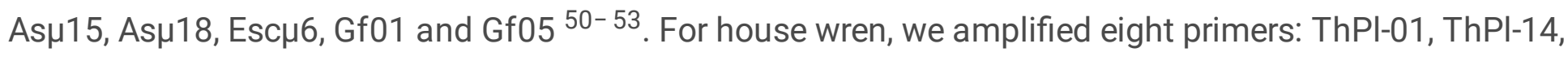
ThPI-17, Ta-C6-7, Ta-B4-2, Ta-A5-2, Ta-A5-15 and Ta-C3(B)-2 ${ }^{54,55}$. Forward primer of each pair was 5' fluorescently labelled. PCR thermal profiles and primer mixes are described in Supplementary Table S3. We amplified all markers in a $12.5 \mu \mathrm{L}$ reaction containing $0.4 \mu \mathrm{M}$ primer mix and $40 \mathrm{ng}$ of template DNA. We used Multiplex Master Kit (Qiagen) for mixed primers and Top Taq Master Kit (Qiagen) for Gf01. We used Veriti ${ }^{\text {TM }}$ thermal cycler (Applied Biosystems, Foster City, CA, USA) to perform the PCR reaction. Capillary electrophoresis was done in a 3500 Genetic Analyzer (Applied Biosystems) at Escuela de Biología, UCR, using Hi-Di ${ }^{\text {TM }}$ Formamide and GeneScan ${ }^{\mathrm{TM}} 500 \mathrm{LIZ}^{\mathrm{TM}}$ dye Size Standard (Applied Biosystems). We scored genotypes using GeneMarker 1.91 (SoftGenetics, State College, PA, USA).

\section{Genetic analysis}


We conducted population genetics analyses in R 4.0.2 ${ }^{56}$, using the RStudio 1.3.180 GUI ${ }^{57}$. We calculated expected heterozygosity $\left(H_{e}\right)$, observed heterozygosity $\left(H_{0}\right)$, inbreeding coefficients $\left(F_{I S}\right)$ and allelic richness $\left(A_{r}\right)$ per population (to compensate for differences in sampling size per population) using the "hierfstat" package ${ }^{58}$. We calculated Weir and Cockerham $\mathrm{F}_{\mathrm{ST}}\left(\theta_{W C}\right)^{59}$, expected heterozygosity values and $95 \%$ confidence interval of both estimates using 9999 bootstrap with boot.vc function of the "hierfstat" package. We also calculated pairwise $\theta_{w c}$ between populations with pairwise. WCfst function and it's $95 \% \mathrm{Cl}$ using boot.ppfst by 9999 bootstrap among loci using the "hierfstat" package.

We visualized individuals' similarity using a discriminant analysis of principal components (DAPC) as implemented in the "adegenet" package ${ }^{60}$. The Bayesian clustering methods in Structure 2.3.4 allowed us to assess the possible genetic clustering of individuals into a $K$ number of clusters ${ }^{61}$. The admixture model and correlated allele frequencies were used, with 300000 markov chains and a burn-in of 30000 . Phase information was added to include $\mathrm{Mme7}$ marker in the analysis, since previous evidence has shown this is a Z-linked marker ${ }^{15,52}$. We tested 1 to 6 clusters with 20 repetitions for each cluster. We determined the most likely number of $\mathrm{K}$ clusters using Structure Harvester $0.6 .94{ }^{62}$ and the Evanno ${ }^{63}$ and $\mathrm{Ln}(\mathrm{K})$ methods. Then, we conducted another structure analysis after determining the most likely $\mathrm{K}$, increasing generations and the burn-in to 1000000 and 100 000, respectively.

\section{Isolation by distance, isolation by resistance and isolation by environment}

To test for isolation by distance (IBD) we estimated the correlation between pairwise Euclidean genetic distances and geographic linear distances among individuals using a Mantel test after 9999 permutations. The same coordinates of the sampling sites were assigned to all individuals within each population.

We estimated landscape resistance to movement and isolation by resistance (IBR) using Circuitscape 4.0.5 ${ }^{64}$. To create the resistance raster, we used a $30 \mathrm{~m}$ resolution land coverage of 2005 shapefile layer of continental Costa Rica created by the Earth Observatory Systems Laboratory of the University of Alberta, based on Landscape 7 satellite image classification and interpretation into 16 categories (Supplementary Table S4), part of Atlas Digital de Costa Rica 2014 project ${ }^{65}$. We also used a $30 \mathrm{~m}$ resolution altitude layer developed by the Atlas Digital de Costa Rica 2008 project raster ${ }^{65}$. To create a resistance grid, we rasterized the land cover into a $100 \mathrm{~m}$ grid and classified the altitude raster into $200 \mathrm{~m}$ elevation categories using ArcGis 10.6. ArcGis toolbox "Gnarly Landscape Utilities", based on resistance values assigned to each land use and altitude categories, according to expert opinion on habitat suitability for both species ${ }^{66}$. As altitude and land use layers overlap, the maximum value of resistance between both layers was assigned to each grid. We performed a pairwise circuit theory analysis of connectivity between all sampling locations of white-eared ground-sparro $w$ and house wren, with a $\log _{10}$ transformation for the cumulative current map for easier visualization. Finally, the correlation between pairwise resistance values and genetic differentiation among individuals was also tested using a Mantel test with 9999 permutations. 
To test for isolation by environment (IBE), we developed a maxent species distribution model using the "Wallace" R library ${ }^{67}$. We obtained the occurrence of each species from the eBird database (www.ebird.org). We then removed duplicated data, erroneous observations, and randomly thinned spatial data to $1 \mathrm{~km}$ for white-eared ground-sparrow and $5 \mathrm{~km}$ for house wren. We used all 19 bioclimatic data available at www.worldclim.org at a $1 \mathrm{~km}^{2}$ resolution. We delimited the area of calibration to $25 \mathrm{~km}$ radius around each occurrence point. We sampled 10000 background points and used the spatially block partition method. We set regularization multiplier parameters from 0.5 to 4 , with 0.5 increments and used 5 feature class combinations ("L", “ $H$ ”, “LQ”, “LQH”, “LQHP”, where "L" = linear, “ $H$ ” = hinge, "Q" = quadratic, " $P$ " = product). We evaluated the models using the area under the curve (AUC) and average 10th percentile omission rate. To convert it into a resistance matrix input for Circuitscape, we performed a cloglog map prediction and set it as conductance in our Circuitscape model. We developed pairwise modeling between all sampling locations of white-eared ground-sparrow and house wren with a $\log _{10}$ transformation for the cumulative current map. We performed a Mantel test with 9999 permutations between individual genetic Euclidean distance and resistance values.

\section{Declarations}

\section{Data availability}

The datasets generated during the current study are available from the corresponding author on reasonable request.

\section{Acknowledgements}

This work was financially supported by Vicerrectoría de Investigación of Universidad de Costa Rica (B9469, C0-517). We would like to thank B. Graham for providing helpful comments on statistical analyses and D. Ocampo for field assistance. This work is part of M. Rodríguez-Bardía MSc. thesis at Universidad de Costa Rica.

\section{Author Contributions}

M.R-B, L.S., E.J.F. and G.B. designed the study. M.R-B. and L.S. collected the samples. M.R-B and R.M-B. performed lab work. M.R-B, R.M-B. and E.J.F. performed statistical and genetic analyses. M.R-B. drafted the manuscript. All authors contributed, completed, and approved the final manuscript.

\section{Competing interests}

The authors declare no competing interests. 


\section{References}

1. Biamonte, E., Sandoval, L., Chacón, E. \& Barrantes, G. Effect of urbanization on the avifauna in a tropical metropolitan area. Landsc. Ecol. 26, 183-194 (2011).

2. Fahrig, L. Effects of habitat fragmentation on biodiversity. Annu. Rev. Ecol. Evol. Syst. 34, 487-515 (2003).

3. Montgomery, M. R. The urban transformation of the developing world. Science 319, 761-764 (2008).

4. Nuissl, H. \& Siedentop, S. Urbanisation and Land Use Change. in Sustainable Land Management in a European Context: A Co-Design Approach (eds. Weith, T. et al.) 75-99 (Springer International Publishing, 2021). doi:10.1007/978-3-030-50841-8_5.

5. Scolozzi, R. \& Geneletti, D. A multi-scale qualitative approach to assess the impact of urbanization on natural habitats and their connectivity. Environ. Impact Assess. Rev. 36, 9-22 (2012).

6. Pauchard, A., Aguayo, M., Peña, E. \& Urrutia, R. Multiple effects of urbanization on the biodiversity of developing countries: The case of a fast-growing metropolitan area (Concepción, Chile). Biol. Conserv. 127, 272-281 (2006).

7. Xu, X., Xie, Y., Qi, K., Luo, Z. \& Wang, X. Detecting the response of bird communities and biodiversity to habitat loss and fragmentation due to urbanization. Sci. Total Environ. 624, 1561-1576 (2018).

8. Bélisle, M. \& St. Clair, C. C. Cumulative effects of barriers on the movements of forest birds. Conserv. Ecol. 5, 9; http://www.consecol.org/vol5/iss2/art9 (2001).

9. Blair, R. B. Land use and avian species diversity along an urban gradient. Ecol. Appl. 6, 506-519 (1996).

10. Tremblay, M. A. \& St. Clair, C. C. Permeability of a heterogeneous urban landscape to the movements of forest songbirds. J. Appl. Ecol. 48, 679-688 (2011).

11. Johnson, M. T. J. \& Munshi-South, J. Evolution of life in urban environments. Science 358, eaam8327 (2017).

12. Isaksson, C. Impact of Urbanization on Birds. in Bird Species. Fascinating Life Sciences (ed. Tietze, D. T.) 235-257 (Springer International Publishing, 2018). doi:10.1007/978-3-319-91689-7_13.

13. Miles, L. S., Rivkin, L. R., Johnson, M. T. J., Munshi-South, J. \& Verrelli, B. C. Gene flow and genetic drift in urban environments. Mol. Ecol. 28, 4138-4151 (2019).

14. Delaney, K. S., Riley, S. P. D. \& Fisher, R. N. A rapid, strong, and convergent genetic response to urban habitat fragmentation in four divergent and widespread vertebrates. PLOS ONE 5, e12767; (2010).

15. Unfried, T. M., Hauser, L. \& Marzluff, J. M. Effects of urbanization on Song Sparrow (Melospiza melodia) population connectivity. Conserv. Genet. 14, 41-53 (2013).

16. Brewer, V. N., Lane, S. J., Sewall, K. B. \& Mabry, K. E. Effects of low-density urbanization on genetic structure in the Song Sparrow. PLOS ONE 15, e0234008 (2020).

17. Björklund, M., Ruiz, I. \& Senar, J. C. Genetic differentiation in the urban habitat: the great tits (Parus major) of the parks of Barcelona city. Biol. J. Linn. Soc. 99, 9-19 (2010). 
18. Perrier, C. et al. Great tits and the city: distribution of genomic diversity and gene-environment associations along an urbanization gradient. Evol. Appl. 11, 593-613 (2018).

19. Tan, D. J. X. et al. Novel genome and genome-wide SNPs reveal early fragmentation effects in an edge-tolerant songbird population across an urbanized tropical metropolis. Sci. Rep. 8, 12804 (2018).

20. McRae, B. H., Dickson, B. G., Keitt, T. H. \& Shah, V. B. Using circuit theory to model connectivity in ecology, evolution, and conservation. Ecology 89, 2712-2724 (2008).

21. Howell, S. N. G. \& Webb, S. A Guide to the Birds of Mexico and Northern Central America. (Oxford University Press, 1995).

22. Sandoval, L. \& Mennill, D. J. Breeding biology of White-eared Ground-sparrow (Melozone leucotis), with a description of a new nest type. Ornitol. Neotropical 23, 225-234 (2012).

23. Stiles, F. G. \& Skutch, A. F. A Guide to the Birds of Costa Rica. (Cornell University Press, 1989).

24. Carlson, T. N. \& Sanchez-Azofeifa, G. A. Satellite remote sensing of land use changes in and around San José, Costa Rica. Remote Sens. Environ. 70, 247-256 (1999).

25. Sánchez, J. E., Criado, J., Sánchez, C. \& Sandoval, L. Costa Rica. in Important Bird Areas of Americas: Priority Sites for Biodiversity Conservation (eds. Davendish, C., Díaz-Fernández, D. F., Clay, R. P., Davidson, I. \& Yépez Zabala.) 149-156 (Birdlife International, 2009).

26. Sandoval, L. et al. The forgotten habitats in conservation: early successional vegetation. Rev. Biol. Trop. 67, 36-52 (2019).

27. Juárez, R., Chacón-Madrigal, E. \& Sandoval, L. Urbanization has opposite effects on the territory size of two passerine birds. Avian Res. 11, 11 (2020).

28. Skutch, A. F. Life history of the Southern House Wren. Condor 55, 121-149 (1953).

29. Johnson, L. S. House Wren (Troglodytes aedon), Version 1.0. in Birds of the World (ed. Poole, A. F.) (Cornell Lab of Ornithology, 2020).

30. Markowski, M. et al. Genetic structure of urban and non-urban populations differs between two common parid species. Sci. Rep. 11, 10428 (2021). https://doi.org/10.1038/s41598-021-89847-4

31. Mueller, J. C. et al. Evolution of genomic variation in the burrowing owl in response to recent colonization of urban areas. Proc. R. Soc. B Biol. Sci. 285, 20180206 (2018).

32. Vangestel, C. et al. Genetic diversity and population structure in contemporary house sparrow populations along an urbanization gradient. Heredity 109, 163-172 (2012).

33. Joyce, A. T. Land Use Change in Costa Rica: 1966 - 2006, as Influenced by Social, Economic, Political, and Environmental Factors. (Litografía e imprenta, SA., 2016).

34. Fuchs, E. J. \& Hamrick, J. L. Mating system and pollen flow between remnant populations of the endangered tropical tree, Guaiacum sanctum (Zygophyllaceae). Conserv. Genet. 12, 175-185 (2011).

35. Stevens, K., Harrisson, K. A., Hogan, F. E., Cooke, R. \& Clarke, R. H. Reduced gene flow in a vulnerable species reflects two centuries of habitat loss and fragmentation. Ecosphere 9, e02114 (2018).

36. Quesada-Román, A., Villalobos-Portilla, E. \& Campos-Durán, D. Hydrometeorological disasters in urban areas of Costa Rica, Central America. Environ. Hazards 20, 264-278 (2021). 
37. Muñoz, P., García-Rodríguez, A. \& Sandoval, L. Urbanization, habitat extension and spatial pattern, threaten a Costa Rican endemic bird. Rev. Biol. Trop. 69, 170-180 (2021).

38. Sandoval, L., Bitton, P. P., Doucet, S. M. \& Mennill, D. J. Analysis of plumage, morphology, and voice reveals species-level differences between two subspecies of Prevost's Ground-sparrow Melozone biarcuata (Prévost and Des Murs) (Aves: Emberizidae). Zootaxa 3895, 103-116 (2014).

39. Arguedas, N. \& Parker, P. G. Seasonal migration and genetic population structure in House Wrens. Condor 102, 517-528 (2000).

40. Pujol, R. \& Pérez, E. Crecimiento urbano en la región metropolitana de San José, Costa Rica. Una exploración espacial y temporal de los determinantes del cambio de uso del suelo, 1986-2010. Lincoln Institute of Land Policy https://www.lincolninst.edu/sites/default/files/pubfiles/2242_1578_Pujol_WP13RP1SP.pdf (2012).

41. Sandoval, L., Dabelsteen, T. \& Mennill, D. J. Transmission characteristics of solo songs and duets in a neotropical thicket habitat specialist bird. Bioacoustics 24, 289-306 (2015).

42. Sandoval, L., Méndez, C. \& Mennill, D. J. Vocal behaviour of White-eared Ground-sparrows (Melozone leucotis) during the breeding season: repertoires, diel variation, behavioural contexts, and individual distinctiveness. J. Ornithol. 157, 1-12 (2016).

43. Garrigues, R. \& Dean, R. The Birds of Costa Rica: A Field Guide. (Cornell University Press, 2014).

44. Sandoval, L., Epperly, K. L., Klicka, J. \& Mennill, D. J. The biogeographic and evolutionary history of an endemic clade of Middle American sparrows: Melozone and Aimophila (Aves: Passerellidae). Mol. Phylogenet. Evol. 110, 50-59 (2017).

45. MacGregor-Fors, I. \& Escobar-Ibáñez, J. F. Birds from Urban Latin America, Where Economic Inequality and Urbanization Meet Biodiversity. in Avian Ecology in Latin American Cityscapes (eds. MacGregor-Fors, I. \& Escobar-Ibáñez, J. F.) 1-10 (Springer International Publishing, 2017). doi:10.1007/978-3-319-63475-3_1.

46. MacGregor-Fors, I. \& García-Arroyo, M. Who Is Who in the City? Bird Species Richness and Composition in Urban Latin America. in Avian Ecology in Latin American Cityscapes (eds. MacGregor-Fors, I. \& Escobar-lbáñez, J. F.) 33-55 (Springer International Publishing, 2017). doi:10.1007/978-3-319-63475-3_3.

47. Lande, R. \& Barrowclough, G. F. Effective Population Size, Genetic Variation, and their Use in Population Management. in Viable Populations for Conservation (ed. Soulé, M. E.) 87-124 (Cambridge University Press, 1987). doi:10.1017/CB09780511623400.007.

48. Newman, D. \& Pilson, D. Increased probability of extinction due to decreased genetic effective population size: experimental populations of Clarkia pulchella. Evolution 51, 354-362 (1997).

49. Longmire, J. L., Maltbie, M. \& Baker, R. J. Use of 'Lysis Buffer' in DNA Isolation and its implication for Museum Collections. (Museum of Texas Tech University, 1997).

50. Bulgin, N. L., Gibbs, H. L., Vickery, P. \& Baker, A. J. Ancestral polymorphisms in genetic markers obscure detection of evolutionarily distinct populations in the endangered Florida grasshopper sparrow (Ammodramus savannarum floridanus). Mol. Ecol. 12, 831-844 (2003). 
51. Hanotte, O. et al. Isolation and characterization of microsatellite loci in a passerine bird: the reed bunting Emberiza schoeniclus. Mol. Ecol. 3, 529-530 (1994).

52. Jeffery, K. J., Keller, L. F., Arcese, P. \& Bruford, M. W. The development of microsatellite loci in the song sparrow, Melospiza melodia (Aves) and genotyping errors associated with good quality DNA. Mol. Ecol. Notes 1, 11-13 (2001).

53. Petren, K. Microsatellite primers from Geospiza fortis and cross-species amplification in Darwin's finches. Mol. Ecol. 7, 1782-1784 (1998).

54. Brar, R. K. et al. Eleven microsatellite loci isolated from the banded wren (Thryothorus pleurostictus). Mol. Ecol. Notes 7, 69-71 (2007).

55. Cabe, P. R. \& Marshall, K. E. Microsatellite loci from the house wren (Troglodytes aedon). Mol. Ecol. Notes 1, 155-156 (2001).

56. R Core Team. R: A language and environment for statistical computing. R Foundation for Statistical Computing https://www.R-project.org/ (2021).

57. RStudio Team. RStudio: integrated development environment for R. RStudio http://www.rstudio.com/ (2021).

58. Goudet, J. hierfstat, a package for $\mathrm{r}$ to compute and test hierarchical F-statistics. Mol. Ecol. Notes 5, 184-186 (2005).

59. Weir, B. S. \& Cockerham, C. C. Estimating F-statistics for the analysis of population structure. Evolution 38, 1358-1370 (1984).

60. Jombart, T. adegenet: a R package for the multivariate analysis of genetic markers. Bioinformatics 24, 1403-1405 (2008).

61. Pritchard, J. K., Stephens, M. \& Donnelly, P. Inference of population structure using multilocus genotype data. Genetics 155, 945-959 (2000).

62. Earl, D. A. \& vonHoldt, B. M. STRUCTURE HARVESTER: a website and program for visualizing STRUCTURE output and implementing the Evanno method. Conserv. Genet. Resour. 4, 359-361 (2012).

63. Evanno, G., Regnaut, S. \& Goudet, J. Detecting the number of clusters of individuals using the software STRUCTURE: a simulation study. Mol. Ecol. 14, 2611-2620 (2005).

64. Shah, V. B. \& McRae, B. Circuitscape: A Tool for Landscape Ecology. in Proceedings of the 7th Python in Science Conference (eds. Varoquaux, G., Vaught, T. \& Millman, J.) 62-65 (2008).

65. Ortiz-Malavasi, E. Atlas Digital de Costa Rica está a disposición del público. Investiga.TEC 23, 16593383 (2015).

66. McRae, B., Shirk, A. \& Platt, J. Gnarly Landscape Utilities: Resistance and Habitat Calculator User Guide. The Nature Conservancy https://circuitscape.org/gnarly-landscape-utilities/ (2013).

67. Kass, J. M. et al. Wallace: A flexible platform for reproducible modeling of species niches and distributions built for community expansion. Methods Ecol. Evol. 9, 1151-1156 (2018). 
Figures

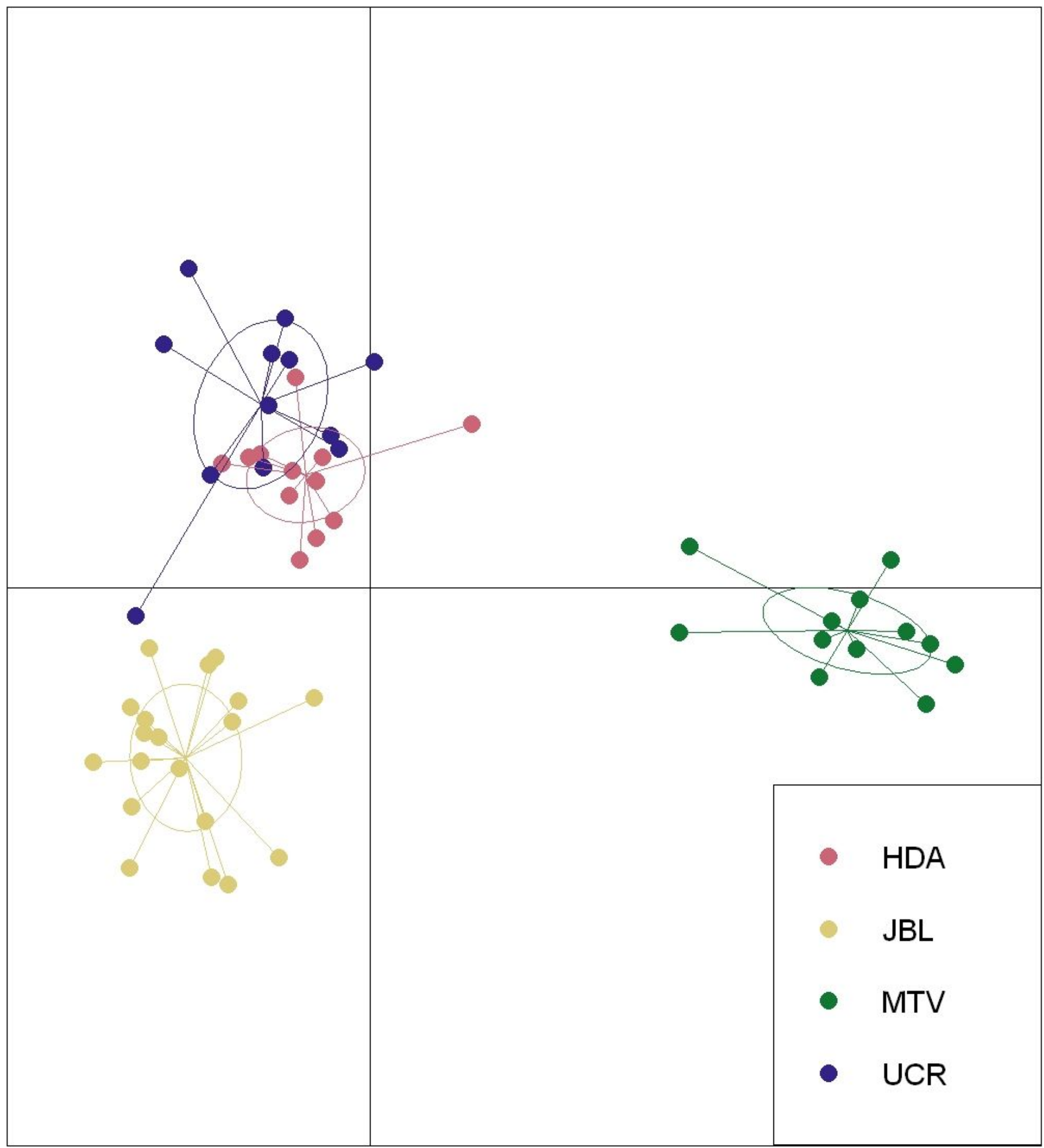

Figure 1

DAPC clustering for individuals of white-eared ground-sparrow (Melozone leucotis) for Heredia (HDA), Lankester Botanical Garden (JBL), Monteverde (MTV) and University of Costa Rica (UCR) populations with priors set as sampling sites. 


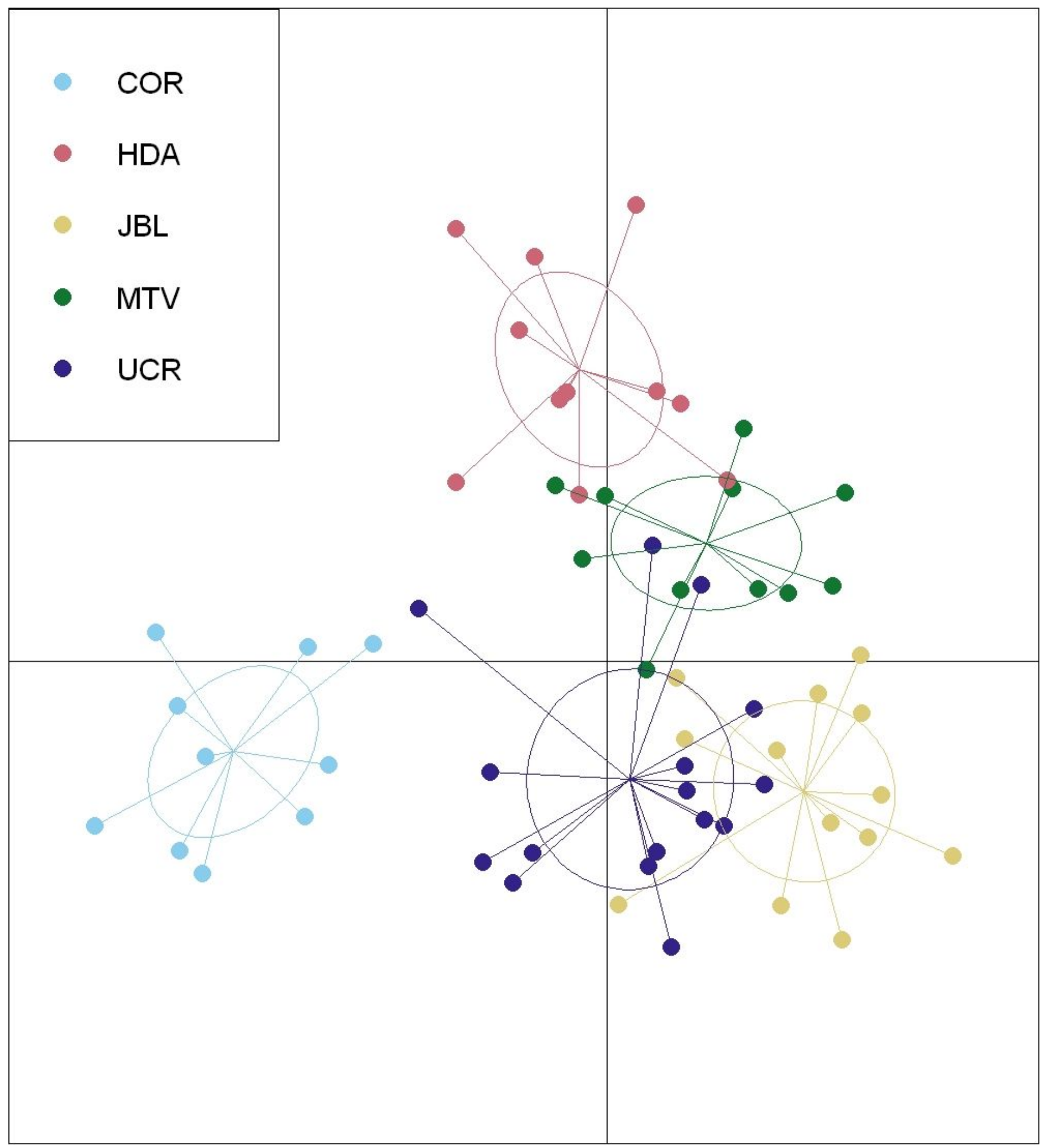

Figure 2

DAPC clustering for individuals of house wren (Troglodytes aedon) for Heredia (HDA), Lankester Botanical Garden (JBL), Monteverde (MTV), University of Costa Rica (UCR) and Corredores (COR) populations with priors set as sampling sites. 


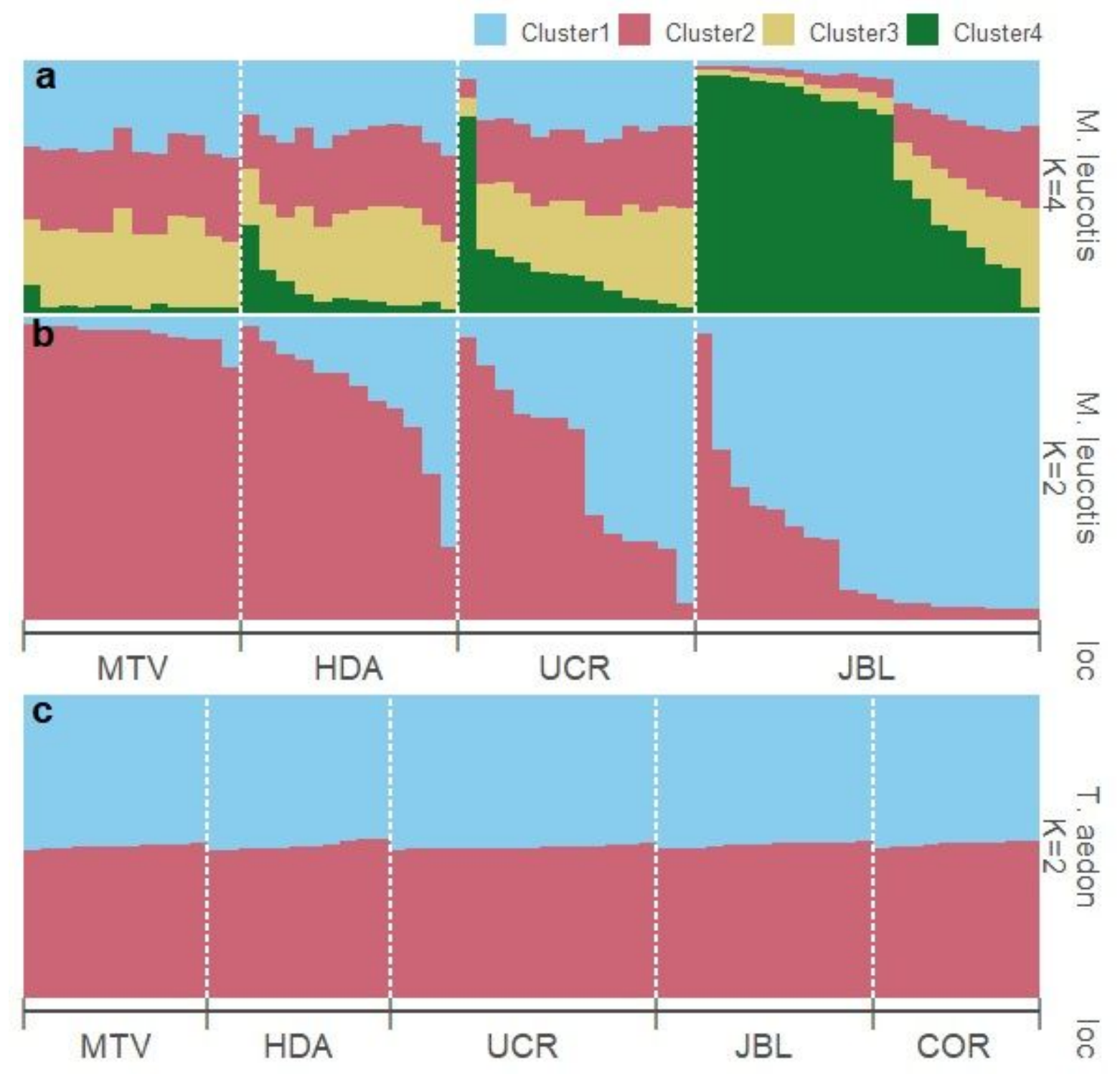

\section{Figure 3}

STRUCTURE barplot for a. white-eared ground-sparrow (Melozone leucotis) $K=4$, b. white-eared groundsparrow $K=2$, and $\mathbf{d}$ house wren (Troglodytes aedon) $K=4$. Plots are sorted by sampling location, bars are sorted by Cluster 1 proportion and each bar represents one individual, while colors represent each cluster, and its size corresponds to assignment proportion. Abbreviations. MTV: Monteverde, HDA: Heredia, UCR: University of Costa Rica, JBL: Lankester Botanical Garden, COR: Corredores. 


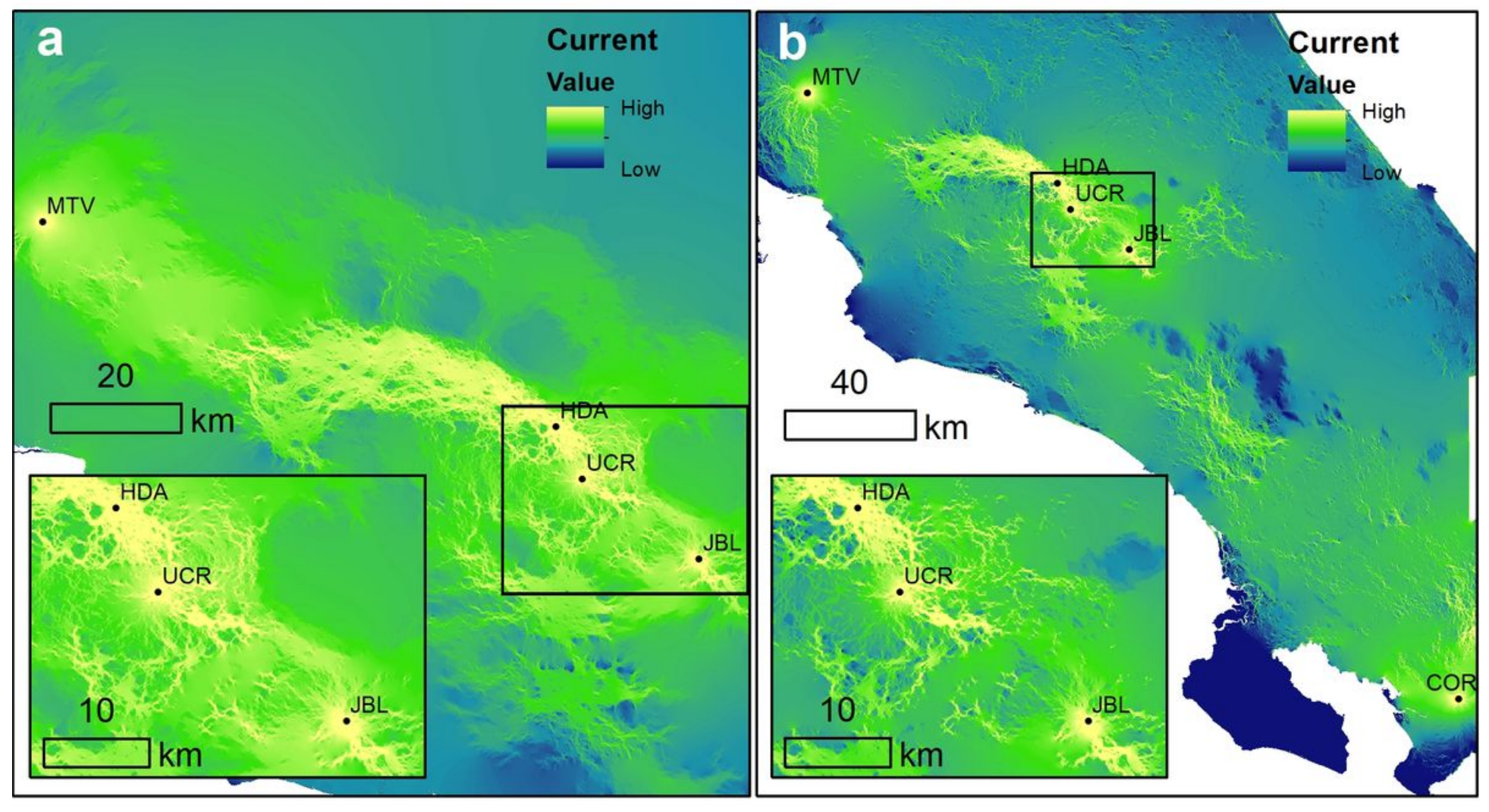

\section{Figure 4}

Maps of cumulative current within sampling site, modelled with circuit theory algorithm using Circuitscape 4.0, based on a land coverage layer of Costa Rica in 2005. Resistance values for each category are described on Supplementary Table S4. a corresponds to white-eared ground-sparrow (Melozone leucotis) sampling sites, and $\mathbf{b}$ house wren (Troglodytes aedon) sampling sites. Abbreviations. MTV: Monteverde, HDA: Heredia, UCR: University of Costa Rica, JBL: Lankester Botanical Garden, COR: Corredores. 


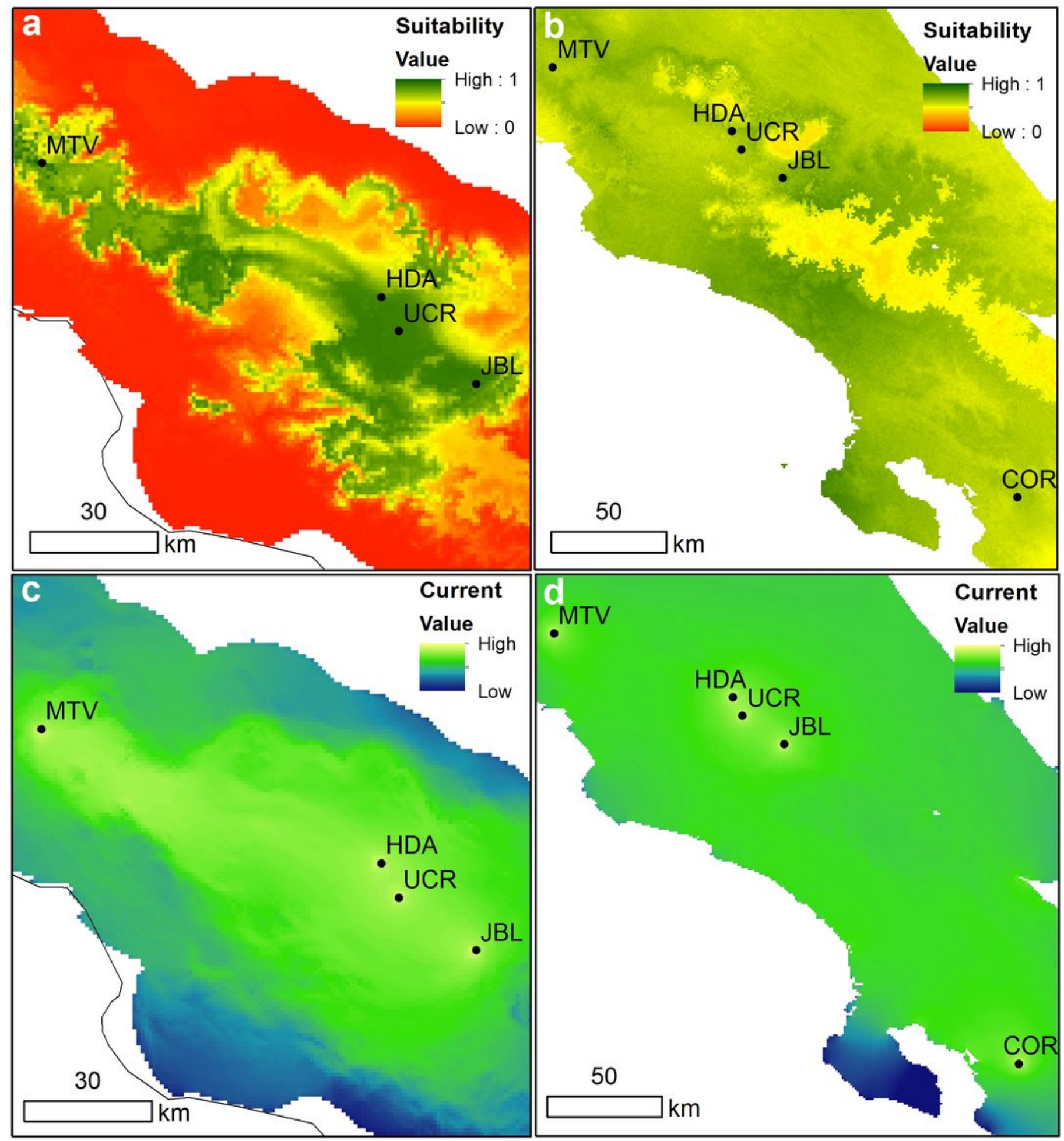

Figure 5

Maps of a-b habitat climatic suitability using MAXENT with clog-log transformation for $\mathbf{a}$. white-eared ground-sparrow (Melozone leucotis) and b. house wren (Troglodytes aedon) in Costa Rica. c-d Represents maps of cumulative current within sampling site, modelled with circuit theory algorithm using Circuitscape 4.0, based on MAXENT climatic suitability prediction for $\mathbf{c}$ white-eared ground-sparrow 
sampling sites and $\mathbf{d}$ house wren sampling sites. Abbreviations. MTV: Monteverde, HDA: Heredia, UCR: University of Costa Rica, JBL: Lankester Botanical Garden, COR: Corredores.

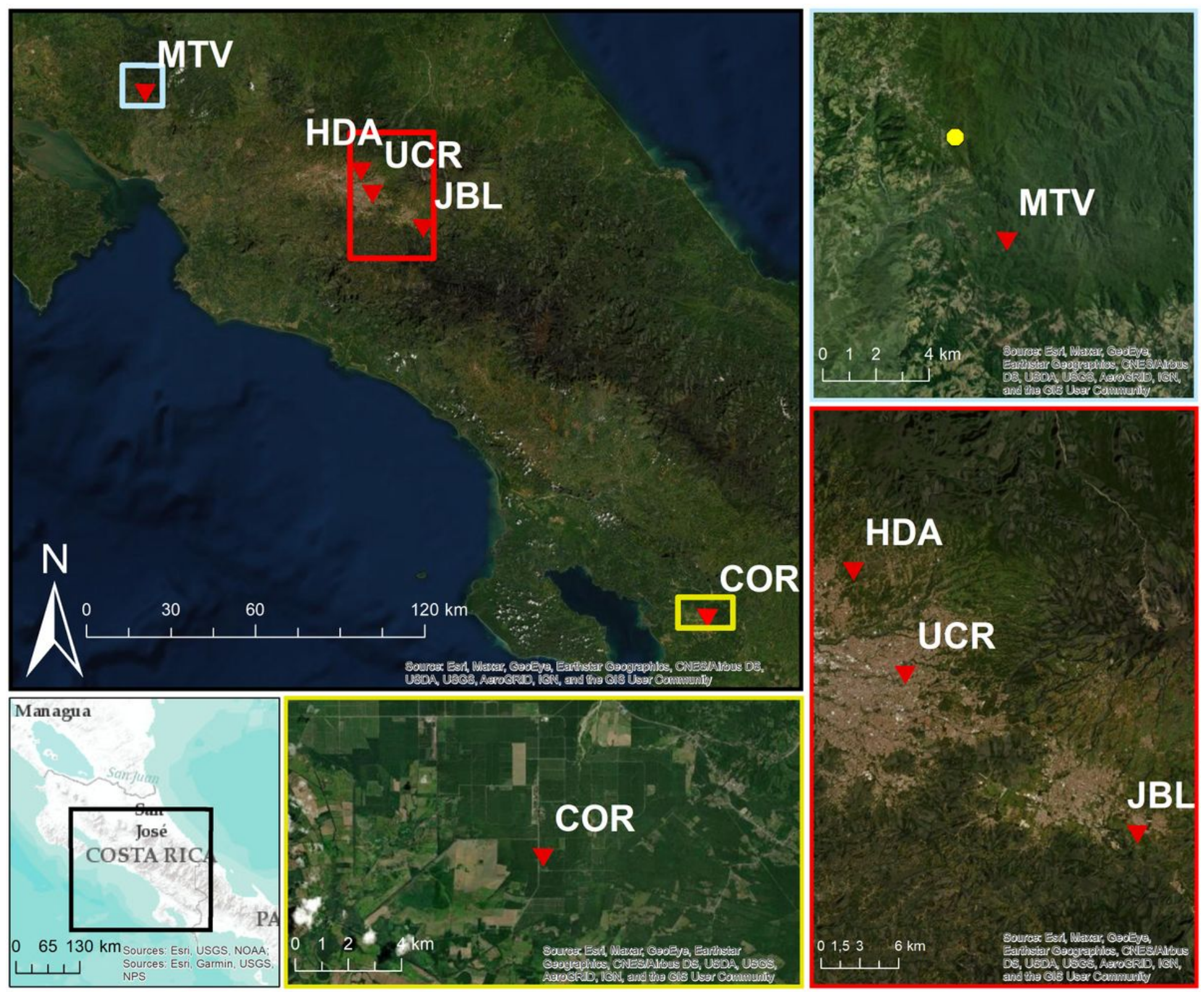

Figure 6

Satellite images of the sampled locations ( $\boldsymbol{\nabla})$. MTV: Monteverde, HDA: Heredia, UCR: University of Costa Rica, JBL: Lankester Botanical Garden, COR: Corredores. ( $)$ corresponds to the MTV sampling location for white-eared ground-sparrow. Images base map source: Esri, Maxar, GeoEye, Earthstar Geographics, CNES/Airbus DS, USDA, USGS, AeroGRID, IGN, Garmin, NOAA, NPS, and the GIS User Community.

\section{Supplementary Files}

This is a list of supplementary files associated with this preprint. Click to download. 
- Supplementary.docx

Page 22/22 